\title{
Chemo-enzymatic synthesis of an original arabinofuranosyl cluster: optimization of the enzymatic conditions
}

\author{
Mélanie Almendros, ${ }^{\text {a,b }}$ Marc François-Heude,,${ }^{\text {a,b }}$ Laurent Legentil,, a,b \\ Caroline Nugier-Chauvin, ${ }^{\mathrm{a}, \mathrm{b}}$ Richard Daniellou, ${ }^{* \mathrm{a}, \mathrm{b}, \mathrm{c}}$ and Vincent Ferrières ${ }^{* \mathrm{a}, \mathrm{b}}$ \\ ${ }^{a}$ Ecole Nationale Supérieure de Chimie de Rennes, CNRS, UMR 6226, \\ Avenue du Général Leclerc, CS 50837, 35708 Rennes cedex 7, France \\ ${ }^{b}$ Université européenne de Bretagne, France \\ ${ }^{c}$ Institut de Chimie Organique et Analytique - ICOA, UMR CNRS 7311, Université d'Orléans, \\ rue de Chartres, BP 6759, 45067 Orléans cedex 2, France \\ E-mail: richard.daniellou@univ-orleans.fr ; vincent.ferrieres@ensc-rennes.fr
}

\section{Dedicated to Professor Richard R. Schmidt on the occasion of his 78th anniversary}

\begin{abstract}
The evaluation of a mutated glycosidase as a major, renewable and eco-friendly partner of the glycosylation reaction allowed the one step synthesis of the arabinofuranosyl cluster 4 in $38 \%$ yield. Our mutated biocatalyst was able to perform coupling to a multivalent bulky substituent with $80 \%$ yield on each arm and pave the way for the further development of enzymatic means of ligation of carbohydrates onto organic scaffolds.
\end{abstract}

Keywords: Furanosides, multipresentation, arabinofuranosidase, thioligation

\section{Introduction}

The surface of all mammalian cells is covered with a diverse range of complex carbohydrates attached to proteins and lipids that are embedded in the cell membrane. ${ }^{1}$ These glycoconjugates form a first line of interaction with the extracellular environment, through their recognition by carbohydrate-binding proteins - lectins - present on other mammalian cells, viruses, bacteria and bacterial toxins. Thus, oligosaccharides are now known for their implication in many important biological processes such as fertilization, inflammatory response, and invasion by pathogens or cancer metastasis for instance. $^{2-4}$ The binding affinity of the glycan-protein interactions for individual monosaccharide is generally very weak, with association constant (Ka) being lower than $10^{6} \mathrm{M}^{-1}$. However, this binding affinity increases synergistically with an increasing number of sugar residues: such phenomena, noted by Lee and co-workers in 1995, are often referred to as 
"the cluster glycoside effect".5-6 A strong glycocluster effect, the result of multivalent interactions, obviously requires a sugar-cluster structure that can present the sugars with proper orientation and spacing. In order to mimic this synergy effect and their biological functions, a variety of glycol-clusters and -dendrimers have been developed. ${ }^{7-8}$ Moreover, the role of these dendrimers are not limited to carbohydrate-protein interactions and they are now of outstanding interest in gene therapy, drug delivery, prion research, magnetic resonance imaging contrast agents and burn treatment, for example. ${ }^{9}$

Thioglycosidic bonds are of great importance in biomolecules and their analogues as their incorporation has led to more stable glycomimetics with potential drug activities. ${ }^{10}$ Until now only chemical methods were available for their incorporation into glycofuranosyl conjugates. ${ }^{11}$ However, enzymatic strategies are becoming an emerging area as notably envisioned by Prof. Schmidt ${ }^{11}$ : "Interest in the use of enzymes, that is, glycosyltransferases, transglycosidases, and glycosidases, and manipulations based on their molecular biology may increase, particularly for the synthesis of specific glycosidic linkages and/or target molecules. Increased understanding of enzyme catalysis will also inspire new general concepts for the chemical regio- and stereoselective formation of glycoside bonds with minimization of the required protecting-group array, as is evident from methods already developed for intramolecular glycosidation." Recently, we described the use of the first thioglycofuranoligase (Araf51 E173A) for the preparation of a great variety of thioaryl derivatives $\mathbf{2}$ in moderate to excellent yields (Scheme 1). ${ }^{12}$ Of great interest, a stable 1-thioimidoyl arabinofuranose $\mathbf{1}$, classically used in chemical glycosylation, was able to efficiently act as donor through an original enzymatic remote activation mechanism. Study of the chemical structure as well as the acidity of the thiol (and thus nucleophilicity of the thiophenolate) allowed us to optimize this biocatalyzed process.

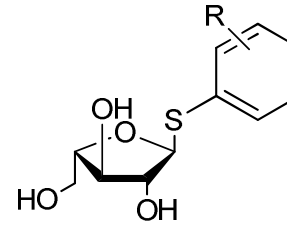

2

9 examples

$50-98 \%$ yields
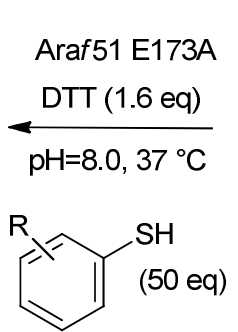

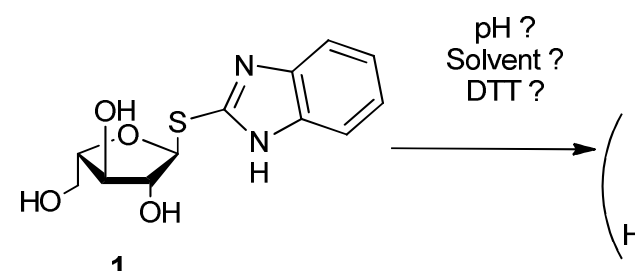

1

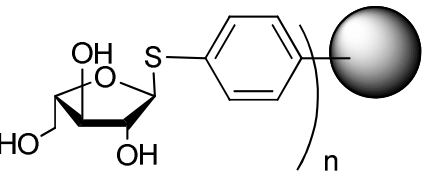

$\mathrm{R}=\mathrm{H}, o-\mathrm{OH}, m-\mathrm{Cl}, m-\mathrm{OMe}, p-\mathrm{Me}, p-\mathrm{Cl}, p-\mathrm{OMe}, p-\mathrm{NH}_{2}, p-\mathrm{COOH}$

Scheme 1. Biocatalyzed synthesis of various thioaryl furanosides.

In the course of our ongoing research, we were then interested in i) increasing the synthetic potency of this mutated enzyme and ii) developing an original, mild and eco-friendly method of thioligation of furanosyl moieties to obtain original glycoclusters. In fact, due to the biological effect of previously published oligosaccharides, such glycoclusters are expected to exhibit improved immunostimulating properties. ${ }^{13-14}$ However, the major drawback of our biocatalyzed 
procedure previously described, demonstrated to rely in the solubility of the thiophenol derivatives thus requiring the use of 50 equivalents. To overcome this problem, conditions of the enzymatic reaction were herein optimized through variations of the $\mathrm{pH}$, the nature of the solvent and the concentration of the anti-oxidative agent dithiothreitol (DTT). Finally, practical application of this enzymatic procedure revealed to be an efficient method of ligation of sugars onto a dendrimeric scaffold that was readily accessible in the laboratory in few chemical steps.

\section{Results and Discussion}

\section{Effect of the pH on the hydrolytic activity of Araf51}

Whereas the Araf51 is a thermophilic enzyme with $\mathrm{T}_{\mathrm{opt}} \sim 82{ }^{\circ} \mathrm{C}$ using 4-nitrophenyl $\alpha$-Larabinofuranoside ( $p$ NP-Ara $f$ ) as a substrate, ${ }^{14}$ we determined its activity at $25{ }^{\circ} \mathrm{C}$, for practical reasons. Determination of the kinetic parameter $K_{\mathrm{m}}$ for the hydrolysis of $p$ NP-Ara $f$ in standard conditions $(0.2 \mathrm{mg} / \mathrm{mL}$ in $50 \mathrm{mM}$ PBS pH 7, $1 \mathrm{mg} / \mathrm{mL}$ BSA $)$ revealed a value of $0.15 \mathrm{mM}(0.25$ $\mathrm{mM}$ at $\left.37{ }^{\circ} \mathrm{C}\right) .{ }^{13}$ Optimum $\mathrm{pH}$ was determined for this reaction using $3 \mathrm{mM}$ as the substrate concentrations and thus appeared to be comprised between 6.5 and 7.0. The enzyme proved to be very active on this artificial substrate revealing a $k_{\text {cat }}$ value of $415 \mathrm{~min}^{-1}$ and a specific activity of $2.8510^{3} \mathrm{~min}^{-1} \mathrm{mM}^{-1}$ in accordance with previous studies. ${ }^{15}$

\section{Solvent effects}

The use of non-aqueous water-miscible co-solvents in such enzyme-catalyzed coupling reactions provides the advantage of solubilising the aromatic substrates targeted as acceptors, as most of them are highly hydrophobic. However to prevent any deactivation of the enzyme, their effects were evaluated on the hydrolytic activity of Araf51. Solvents, essentially polar ones, possessing different properties ( $\log \mathrm{P}$, dielectric constant $\varepsilon$, dipolar moment $\mu$ ) were examined (Table 1 ).

Table 1. Log $\mathrm{P}$ (logarithm of the partition coefficient of a given solvent between 1-octanol and water), $\varepsilon, \mu$ values of the tested co-solvents

\begin{tabular}{cccc}
\hline Solvent & $\log P$ & $\varepsilon$ & $\mu$ \\
\hline Water & - & 81 & 1.9 \\
DMSO & -1.35 & 49 & 4.03 \\
DMF & -1.01 & 36.7 & 3.9 \\
ACN & -0.447 & 37.5 & 3.92 \\
THF & -0.327 & 7.4 & 1.8 \\
1,4-Dioxane & -0.271 & 2.2 & 0.45 \\
\hline
\end{tabular}

We evaluated their effects depending on their dielectric constant $\varepsilon$ and their $\log \mathrm{P}$ value, suspecting an important influence of their dissociation power and their hydrophilic properties on 
the enzyme-substrates system as well as on the reaction process. In a typical Araf51-catalyzed hydrolytic reaction of the $p \mathrm{NP}$-Araf model substrate, assays were performed in the optimized conditions of temperature and $\mathrm{pH}$, including $10 \%$ of a co-solvent and the hydrolytic activity was measured for a continuous $10 \mathrm{~min}$-period by monitoring the released 4-nitrophenolate spectrophotometrically. In all buffer/co-solvent monophasic systems, the enzyme was partially or fully active (Figure 1). This activity appeared to be significantly lowered in the THF and 1,4dioxane co-solvent systems (up to $50 \%$ of the remaining activity at $10 \mathrm{~min}$ ) it did not seem to be really affected in the presence of the more polar and dissociating ACN. Moreover, DMF and DMSO, which exhibit the lowest $\log \mathrm{P}$ values of all the solvents investigated $(\log \mathrm{P}<-1)$, caused an apparent activation or stabilization of the catalyst, especially important for DMSO (around $26 \%$ at $10 \mathrm{~min}$ ). These results could thus be examined on the basis of the hydrophobicity of the solvent, for which the most reliable parameter used so far is the Log P. ${ }^{16}$

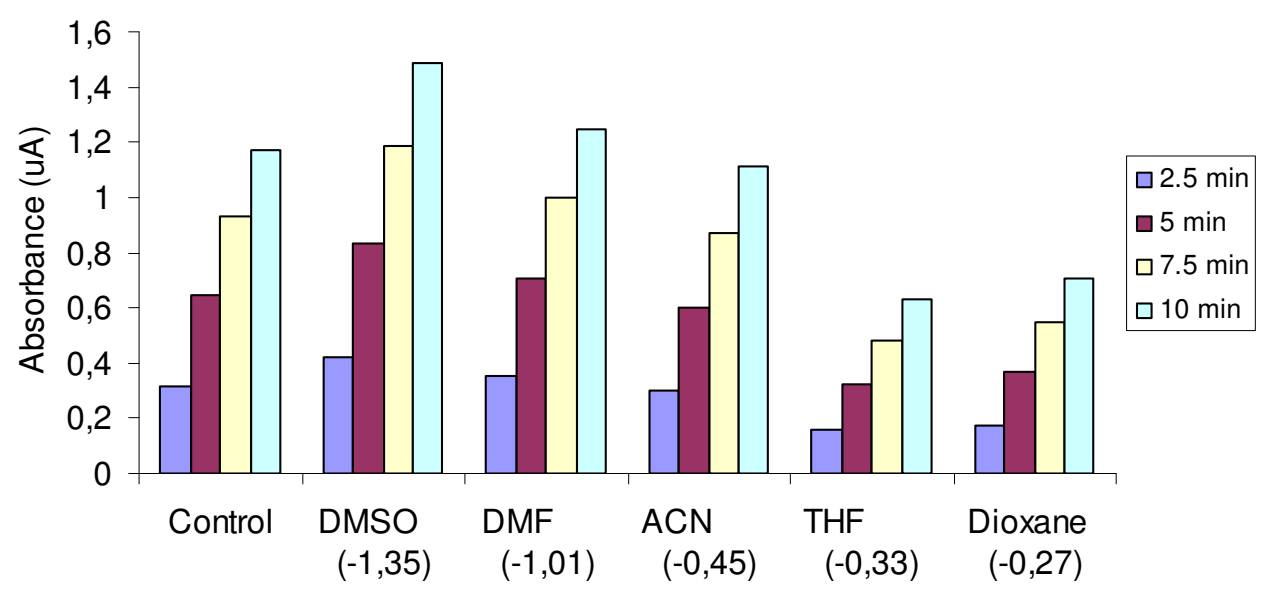

Figure 1. Effects of the $10 \%(\mathrm{v} / \mathrm{v})$ added organic co-solvents on the Araf51-catalyzed hydrolysis of $p$ NP-Araf for a continuous $10 \mathrm{~min}$ period. The organic solvents are listed according to increasing $\log \mathrm{P}$ value ( $\mathrm{P}=$ partition coefficient between $n$-octanol and water) from left to right. Log $\mathrm{P}$ values appear in brackets under the solvent.

To study the effect of the DMSO in more detail, hydrolytic activity was measured at varied DMSO concentrations (10 to $50 \% \mathrm{v} / \mathrm{v}$ ) for a $10 \mathrm{~min}$ conversion of $p$ NP-Araf by the enzyme (Figure 2).

The $p$ NP-Ara $f$ conversion constantly increased with the increasing amount of DMSO in the media until the $25 \% \mathrm{v} / \mathrm{v}$ proportion. The influence of the DMSO amount on the hydrolytic activity of the enzyme appeared to be time-dependent. Indeed, in comparison with hydrolytic activity of Araf51 in the buffer solution alone (control), with 25\% DMSO added, the enzyme activity was at an optimum reaching an excess of $60 \%$ increased activity compared to the control at 10 minutes. Higher and lower percentages of DMSO did not improve the activity. In the 
biocatalysts literature, water-miscible hydrophilic solvents such as DMF or DMSO are usually incompatible with enzymatic activity, especially for some glycosylhydrolases. ${ }^{17}$ On the contrary, and as already mentioned for others enzymes, the positive effect of DMSO at certain proportion observed in our case, may be attributed to stabilization of the enzyme. ${ }^{18}$ In our case, the maximum of $25 \%$ could certainly be considered as the optimized one that afford the better solubility of substrates in the media.

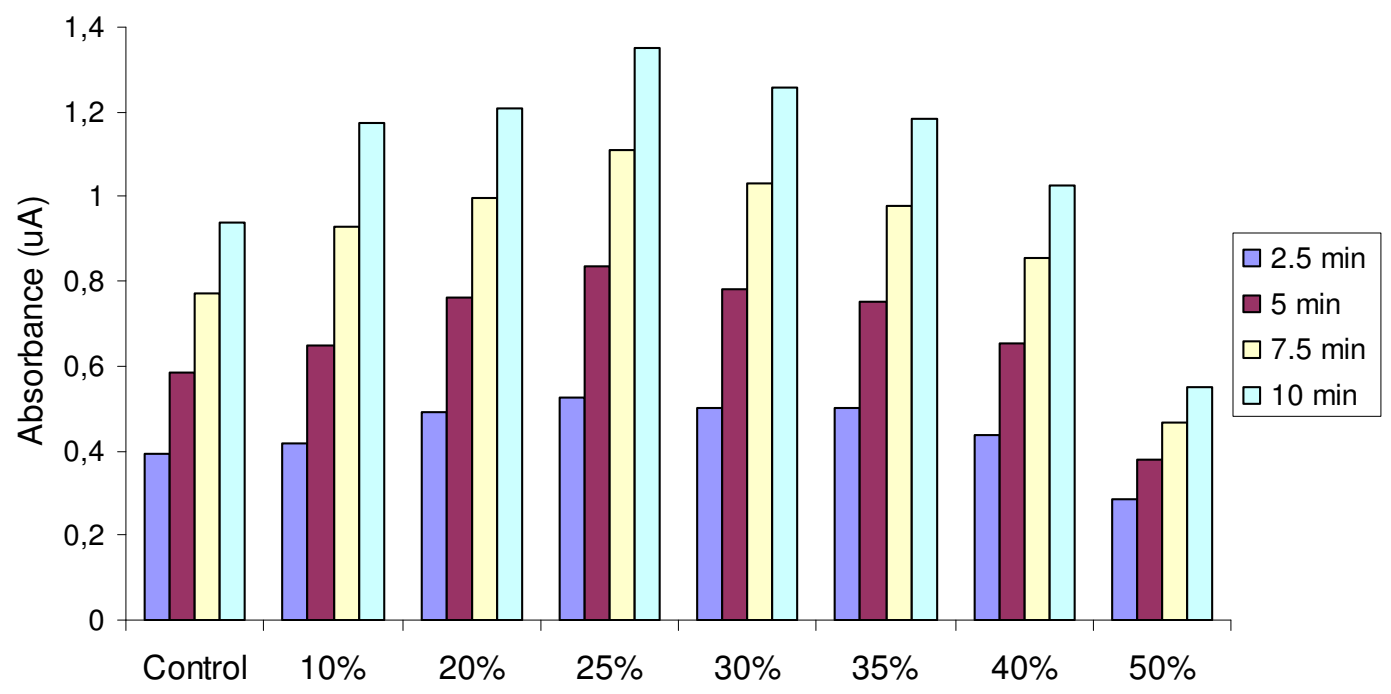

Figure 2. Influence of the amount of DMSO on the Araf51-catalyzed hydrolysis of $p$ NP-Araf at $2.5,5,7.5$ and $10 \mathrm{~min}$.

\section{DTT effects}

While working under reasonably oxygen-free conditions to avoid the otherwise rapid oxidation of sulphur compounds into disulfide derivatives, DTT was added in the media during the coupling reactions. We thus examined the likely influence of DTT on the on the hydrolytic activity of Araf51 as it might reduce the disulfide bonds of the protein. The previous reaction conditions were used to test different concentrations of DTT ranging from 0.5 to $100 \mathrm{mM}$ (Figure 3). In comparison with hydrolytic activity of Araf51 in the buffer solution alone (control), we measured a gentle increasing of the enzymatic activity up to $10 \%$ between 2.5 min and 10 min of reaction when DTT was present at the final concentration of 0.5 to $5 \mathrm{mM}$. The influence of the DTT concentrations greater than $5 \mathrm{mM}$, on the hydrolytic activity of the enzyme appeared to be time-dependent. We observed a considerably decreased activity up to $54 \%$ at 10 min when DTT concentration reached $100 \mathrm{mM}$. Conclusively, the optimized proportion of DTT in order to prevent any oxidation of sulphur compounds in the coupling reactions as well as to avoid any enzyme deactivation could be estimated at $1 \mathrm{mM}$. 


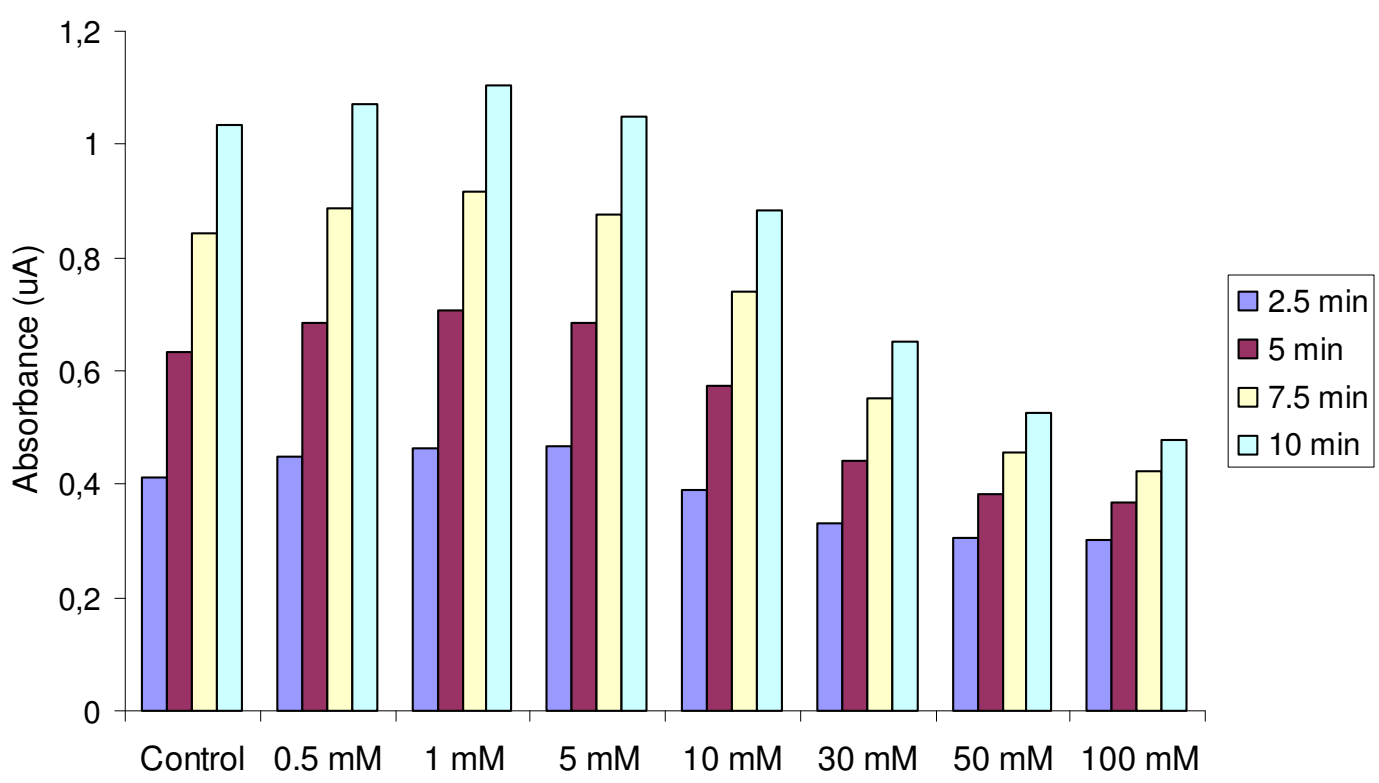

Figure 3. Influence of the concentration of DTT on the Araf51-catalyzed hydrolysis of $p$ NP-Araf at $2.5,5,7.5$ and $10 \mathrm{~min}$.

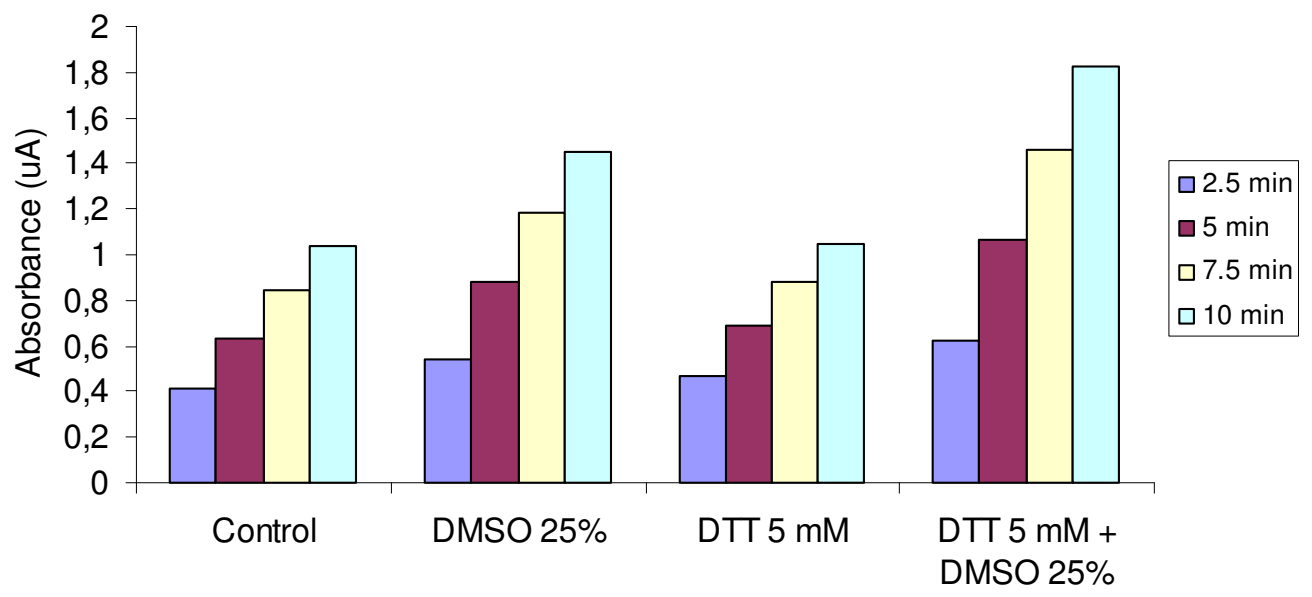

Figure 4. Combined effects of DMSO 25\% and DTT $5 \mathrm{mM}$ on the Araf51-catalyzed hydrolysis of $p$ NP-Araf at 2.5, 5, 7.5 and $10 \mathrm{~min}$.

Finally, the combined effects of the optimized DTT $5 \mathrm{mM}$ and DMSO $25 \%$ on the hydrolytic activity of Araf51 were evaluated at different reaction times from 2.5 to $10 \mathrm{~min}$ (Figure 4). Surprisingly, we measured an additive effect of both DTT and DMSO in these conditions leading to an optimized hydrolytic activity of $52 \%$ and $76 \%$ at 2.5 and $10 \mathrm{~min}$ respectively in comparison with the free solvent control. To our knowledge, this constitutes the first report of such an additive effect and its rationalization will need further experiments. 


\section{Chemo-enzymatic synthesis of the arabinofuranosylcluster 4}

Different research groups showed that poly- and oligosaccharides bind rather weakly with their receptors resulting in a weak activity. In order to overcome such low affinity, we propose to attach arabinofuranosyl moieties to a dendrimeric erythritol support via a well-defined thiolinker. The new created entities should exhibit higher bioactivities due to the well-known cluster effect. ${ }^{7}$ Pentaerythritol constitutes an interesting support for carbohydrates due to the versatility of the functionalization available. ${ }^{19-20}$ Therefore this latter was derivatize through acidic esterification to afford the tetrakis(4-mercaptophenylacetate) $\mathbf{3}$ bearing four thiophenol arms with $35 \%$ yield. Thereafter, the optimized enzymatic conditions i.e. $\mathrm{pH}=7.0,25 \% \mathrm{DMSO}$ and $1 \mathrm{mM}$ of DTT, where applied in the presence of $\mathbf{1}$ to afford the tetra-substituted glycocluster $\mathbf{4}$ with $38 \%$ yield. Solubility of the bulky acceptor was increased by the utilization of $25 \%$ DMSO in the reaction mixture. It was worth noticed that only one equivalent of donor per thiophenol arm was necessary for the linkage. No di- or mono-branched arabinofuranosyl erythritol derivatives were isolated, only traces of the trisubstituted cluster were observed using mass sprectra analysis of the crude reaction mixture.

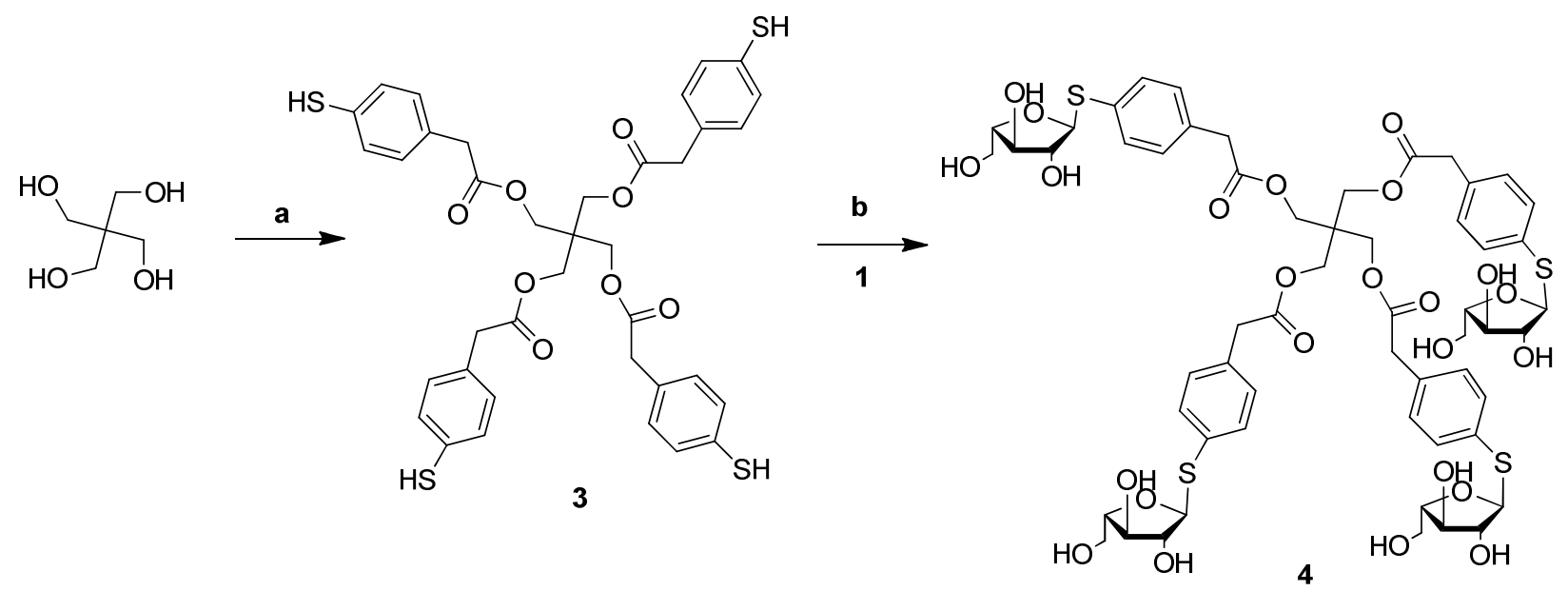

Scheme 2. Access to L-arabinofuranosyl-erythritol dendrimer 4 using Araf51 E173A. Reagents and conditions: (a) 4-mercaptophenylacetic acid, $\mathrm{H}_{2} \mathrm{SO}_{4}$, toluene, reflux, 35\%. (b) 1 (4 eq), Araf51 E173A (0.22 mg/mL), DTT $1 \mathrm{mM}$, tris(hydroxymethyl)aminomethane/ $\mathrm{HCl}$ buffer (50 $\mathrm{mM}, \mathrm{pH} 8)$, DMSO $25 \%, 37{ }^{\circ} \mathrm{C}, 38 \%$.

\section{Conclusions}

The evaluation of thioligase Araf51 E173A as a major, renewable and eco-friendly partner of the glycosylation reaction allowed the one step synthesis of important arabinofuranosyl cluster 4. Our mutated biocatalyst was able to perform coupling to multivalent bulky substituent with $80 \%$ yield on each arm. To our knowledge, this is the first time that such a arabinofuranosyl-conjugate 
is described and obtained through enzymatic means. Our results pave the way for the further development of enzymatic means of ligation of carbohydrates onto organic scaffolds.

\section{Experimental Section}

General. Thin layer chromatography (TLC) analyses were conducted on E. Merck $60 \mathrm{~F}_{254}$ Silica Gel non activated plates and compounds were visualized by UV-absorption at $254 \mathrm{~nm}$ and a 5\% solution of orcinol in $5 \%$ solution of $\mathrm{H}_{2} \mathrm{SO}_{4}$ in $\mathrm{EtOH}$ followed by heating. Preparative chromatography purifications were performed on Geduran Si 60 (40-63 $\mu \mathrm{m})$ Silica Gel. Optical rotations were measured on a Perkin-Elmer 341 polarimeter. NMR spectra were recorded with a Brüker ARX 400 spectrometer at $400 \mathrm{MHz}$ for ${ }^{1} \mathrm{H}$ and $100 \mathrm{MHz}$ for ${ }^{13} \mathrm{C}$. Chemical shifts are given in $\delta$-units (ppm) measured from the solvent signal. Coupling constants $J$ were calculated in Hertz (Hz). Abbreviations were used to precise signal multiplicity: s (singlet), $d$ (doublet), $t$ (triplet), m (multiplet), dd (doublet doublet). Mass spectra were measured with a MS/MS ZabSpec TOF Micromass using $m$-nitrobenzylic alcohol as a matrix and accelerated caesium ions for ionization.

Expression and purification of Araf51 and mutant derivatives. Araf51A protein was produced in Escherichia coli strains BL21 DE3 cells harbouring the appropriate recombinant plasmid, cultured in LB (Luria-Bertani) broth containing $50 \mathrm{mg} / \mathrm{l} \mathrm{kanamycin}$ at $37{ }^{\circ} \mathrm{C}$. Cells were grown to mid-exponential phase $\left[\mathrm{A}_{600}\right.$ (absorbance) of 0.7$]$, at which point isopropyl $\beta$-Dthiogalactopyranoside was added to a final concentration of $1 \mathrm{mM}$ and the cultures were incubated for a further $16 \mathrm{~h}$ at $37^{\circ} \mathrm{C}$. The cells were harvested by centrifugation at $4{ }^{\circ} \mathrm{C}$ during 30 min and recombinant proteins were purified from cell-free extracts by sonication following a 15 min heat denaturation step at $70{ }^{\circ} \mathrm{C}$. Then a last centrifugation at $4{ }^{\circ} \mathrm{C}$ during 30 min was done.

Influence of the cosolvent. All assays were carried out using $p$ NP-Araf (4-nitrophenyl- $\alpha$-Larabinofuranoside; Sigma) and in triplicate. To test the influence of a cosolvent on the Araf51 activity, the standard reaction conditions comprised $50 \mathrm{mM}$ phosphate buffer brought to $\mathrm{pH} 7.0$, containing $1 \mathrm{mg} / \mathrm{ml} \mathrm{BSA}$ and substrate concentration of $1.5 \mathrm{mM}$ (10 times the $\mathrm{K}_{\mathrm{m}}$ value) in $10 \%$ solvent. The different solvents tested were acetonitrile, dioxane, dimethylformamide, dimethyl sulfoxide and tetrahydrofuran. The release of 4-nitrophenate was monitored in $\mathrm{A}_{405}$ after the addition of $0.02 \mathrm{mg} / \mathrm{ml}$ Araf51.

Influence of DMSO. To test the influence of the percentage of DMSO on the Araf51 activity, the previously standard reaction conditions were used with a DMSO concentration ranged from 20 to $50 \%$. The release of 4-nitrophenate was monitored in $\mathrm{A}_{405}$ after the addition of $0.02 \mathrm{mg} / \mathrm{ml}$ Araf51.

Influence of DTT. To test different concentrations of dithiothreitol on the Araf51 activity, the previously standard reaction conditions were used with a DTT concentration ranged from 0.5 to 
$100 \mathrm{mM}$. The release of 4-nitrophenate was monitored in $\mathrm{A}_{405}$ after the addition of $0.02 \mathrm{mg} / \mathrm{ml}$ Araf51.

2,2,2,2-Tetra-(4'-mercaptophenyl acetic acid) ethyl ether (3). To a mixture of erythritol (131 $\mathrm{mg}, 0.959 \mathrm{mmol})$ and 4-mercaptophenylacetic acid $(500 \mathrm{mg}, 2.97 \mathrm{mmol}, 3 \mathrm{eq}$.$) in toluene (5 \mathrm{~mL})$ was added concentrated sulfuric acid $(5,11 \mu \mathrm{L}, 0,096 \mathrm{mmol})$. The flask was fitted with a DienStark apparatus and the mixture refluxed for $12 \mathrm{~h}$. Then, the solution was cooled to RT and successively washed with a saturated solution of $\mathrm{NaHCO}_{3}(2 \times 5 \mathrm{~mL})$, and a brine $(5 \mathrm{~mL})$. The organic phase was dried over $\mathrm{MgSO}_{4}$ and evaporated to give the desired product as a brown oil (220 mg, 31\%). ${ }^{1} \mathrm{H}$ NMR $\left(\mathrm{CDCl}_{3}\right): \delta 7.20$ (d, 8H, J $\left.8 \mathrm{~Hz}, \mathrm{H}-\mathrm{Ph}\right), 7.04$ (d, 8H, J $\left.8 \mathrm{~Hz}, \mathrm{H}-\mathrm{Ph}\right), 3.92$ (s, 8H, $\mathrm{CH}_{2} \mathrm{O}$ ), 3.47 (s, 8H, $\mathrm{CH}_{2} \mathrm{CO}$ ), 3.44 (s, 4H, SH). ${ }^{13} \mathrm{C} \mathrm{NMR}\left(\mathrm{CDCl}_{3}\right): \delta 170.3(\mathrm{CO}), 132.3$, 130.6, 129.2, $127.6\left(\mathrm{C}_{6} \mathrm{H}_{5}\right), 62.0\left(\mathrm{CH}_{2} \mathrm{O}\right), 42.0\left[\mathrm{C}\left(\mathrm{CH}_{2}\right)_{4}\right], 40.3\left(\mathrm{CH}_{2} \mathrm{CO}\right)$. HRESIMS: Calcd for $\mathrm{C}_{37} \mathrm{H}_{36} \mathrm{NaO}_{8} \mathrm{~S}_{4}[\mathrm{M}+\mathrm{Na}]^{+}: m / z$ 759.1191, found: $m / z$ 759.1203.

2,2,2,2-Tetra-(4'-phenylacetic acid-1-thio- $\alpha$-L-arabinofuranoside) ethyl ether (4). Compound 1 (40.0 mg, $141.6 \mu \mathrm{mol}$ ) was dissolved in a tris(hydroxyméthyl)aminomethane/HCl buffer $(50 \mathrm{mM}, \mathrm{pH} 8,10 \mathrm{~mL})$ containing $1 \mathrm{mM}$ of DTT. To the mixture were successively added at $37{ }^{\circ} \mathrm{C}$ the enzyme Araf51 E173A $(0.22 \mathrm{mg} / \mathrm{mL}, 45 \mathrm{nmol}, 5 \mathrm{~mL})$ freshly warmed at $37^{\circ} \mathrm{C}$, and $3(26.1 \mathrm{mg}, 35.4 \mu \mathrm{mol})$ in DMSO $(3.3 \mathrm{~mL})$. After stirring for $3 \mathrm{~h}$ at $37{ }^{\circ} \mathrm{C}$, the reaction mixture was concentrated under reduced pressure and the residue was chromatographically purified on Sephadex G-25 $\left(100 \% \mathrm{H}_{2} \mathrm{O}\right)$ to afford the desired glycocluster 4 as a colourless oil (17.0 $\mathrm{mg}$, 38\%): $[\alpha]_{\mathrm{D}}{ }^{20}-42.9(c 0.28, \mathrm{MeOH}) ; \mathrm{R}_{f} 0.4\left(9: 1 \mathrm{CH}_{2} \mathrm{Cl}_{2} / \mathrm{MeOH}\right) .{ }^{1} \mathrm{H}$ NMR $\left(\mathrm{CD}_{3} \mathrm{OD}\right): \delta 7.50(\mathrm{~d}$, $8 \mathrm{H}, J 8.2 \mathrm{~Hz}, \mathrm{H}-2^{\prime}, \mathrm{H}^{-6}$ ), 7.28 (d, 8H, H-3', H-5'), 5.25 (d, 4H, J1,2 $4.7 \mathrm{~Hz}, \mathrm{H}-1$ ), 3.99 (dd, 4H, $\left.J_{2,3} 4.8 \mathrm{~Hz}, \mathrm{H}-2\right)$ ) 3.97-3.93 (m, 4H, H-4), 3.93 (dd, 4H, $\left.J_{3,4} 7.2 \mathrm{~Hz}, \mathrm{H}-3\right), 3.78$ (dd, 4H, $J_{5 \mathrm{a}, 5 \mathrm{~b}}$ 12.0, $\left.J_{4,5 \mathrm{a}} 2.4 \mathrm{~Hz}, \mathrm{H}-5 \mathrm{a}\right), 3.65$ (dd, 4H, $\left.J_{4,5 \mathrm{~b}} 4.6 \mathrm{~Hz}, \mathrm{H}-5 \mathrm{~b}\right), 3.58$ (bs, 8H, H-7'), 3.50 (bs, 8H, H$\left.9^{\prime}\right) .{ }^{13} \mathrm{C}$ NMR $\left(\mathrm{CD}_{3} \mathrm{OD}\right): \delta 174.7\left(\mathrm{C}-8^{\prime}\right), 136.1\left(\mathrm{C}-4^{\prime}\right), 134.8\left(\mathrm{C}-1^{\prime}\right), 133.0\left(\mathrm{C}-2^{\prime}, \mathrm{C}-6^{\prime}\right), 130.9(\mathrm{C}-$ 3', C-5'), 93.1 (C-1), 84.3 (C-4), 83.3 (C-2), 77.7 (C-3), 64.6 (C-9'), 62.4 (C-5), 46.7 (C-10'), 43.5 (4C-7'). HRESIMS: Calcd for $\mathrm{C}_{57} \mathrm{H}_{68} \mathrm{NaO}_{24} \mathrm{~S}_{4}[\mathrm{M}+\mathrm{Na}]^{+}: \mathrm{m} / z$ 1287.2881, found: $\mathrm{m} / z$ 1287.2885 .

\section{Acknowledgements}

We are grateful to the Agence Nationale de la Recherche (ANR JCJC06_140075) for financial supports and for a grant to M. A. We also thank Jean-Paul Guégan (ENSCR) for recording NMR spectra.

\section{References}

1. Varki, A. Glycobiology 1993, 3, 97.

2. Lis, H.; Sharon, N. Chem. Rev. 1998, 98, 637. 
3. Bertozzi, C. R.; Kiessling, L. L. Science 2001, 291, 2357.

4. Varki A.; Cummings R. D.; Esko J. D.; Freeze H. H.; Stanley P.; Bertozzi C. R.; Hart G. W.; Etzler M. E.. Essentials of Glycobiology, $2^{\text {nd }}$ Edn.; Cold Spring Harbor: New York. 2009.

5. Lee, Y. C. Carbohydr. Res. 1978, 67, 509.

6. Lee, Y. C.; Lee, R. T. Acc. Chem. Res.1995, 28, 321.

7. Lundquist, J. J.; Toone, E. J. Chem. Rev. 2002, 102, 575.

8. Dondoni, A.; Marra, A. Chem. Rev. 2010, 110, 4949.

9. Diekmann, S.; Lindhorst, T. K. Rev. Mol. Biotechnol. 2002, 90, 157 and following references.

10. Pachamuthu, K.; Schmidt, R. R. Chem. Rev. 2006, 106, 160.

11. Zhu, X. M.; Schmidt, R. R. Angew. Chem. Int. Ed. 2009, 48, 1900.

12. Almendros, M. ; Danalev, D. ; François-Heude, M.; Loyer, P.; Legentil, L.; NugierChauvin, C.; Daniellou, R.; Ferrières, V. Org. Biomol. Chem. 2011, 9, 8371.

13. Chlubnova, I. ; Filipp, D. ; Spiwok, V.; Dvorakova, H.; Daniellou, R.; Nugier-Chauvin, C.; Kralova, B.; Ferrières, V. Org. Biomol. Chem. 2010, 8, 2092.

14. Chlubnova, I.; Sylla, B.; Daniellou, R.; Nugier-Chauvin, C.; Legentil, L.; Kralova, B.; Ferrières, V. Nat. Prod. Rep. 2011, 28, 937.

15. Taylor, E. J.; Smith, N. L.; Turkenburg, J. P.; D’Souza, S.; Gilbert, H. J.; Davies, G. J. Biochem. J. 2006, 395, 31.

16. Laane, C.; Boeren, S.; Vos, K.; Veeger, C. Biotechnol. Bioeng. 1987, 30, 81.

17. Faber, K. Biotransformations in Organic Chemistry 5th Ed. Springer-Verlag, 2005.

18. Lavandera, I.; Kern, A.; Schaffenberger, M.; Gross, J.; Glieder, A.; de Wildeman, S.; Kroutil, W. Chem. Sus. Chem. 2008, 1, 431.

19. Schmidt, M.; Dobner, B.; Nuhn, P. Eur. J. Org. Chem. 2002, 669.

20. Liu, B.; Roy, R. Tetrahedron 2001, 57, 6909. 